Supporting Information for

Synthesis and Characterization of Fatty Acid Amides from Commercial Vegetable Oils and Primary Alkyl Amines for Phase Change Material (PCM) Applications

Daniela Betancourt-Jimenez $\ddagger$, Jeffrey P. Youngblood $\ddagger$, and Carlos J. Martinez $z^{\ddagger}$

$\ddagger$ SchoolofMaterials Engineering, Purdue University, West Lafayette, Indiana47907, United

States

The Supporting Information consists of 10 figures and 11 tables in a total of 29 pages 
Reaction scheme for the synthesis of FAAms from vegetable oils and primary alkyl amines
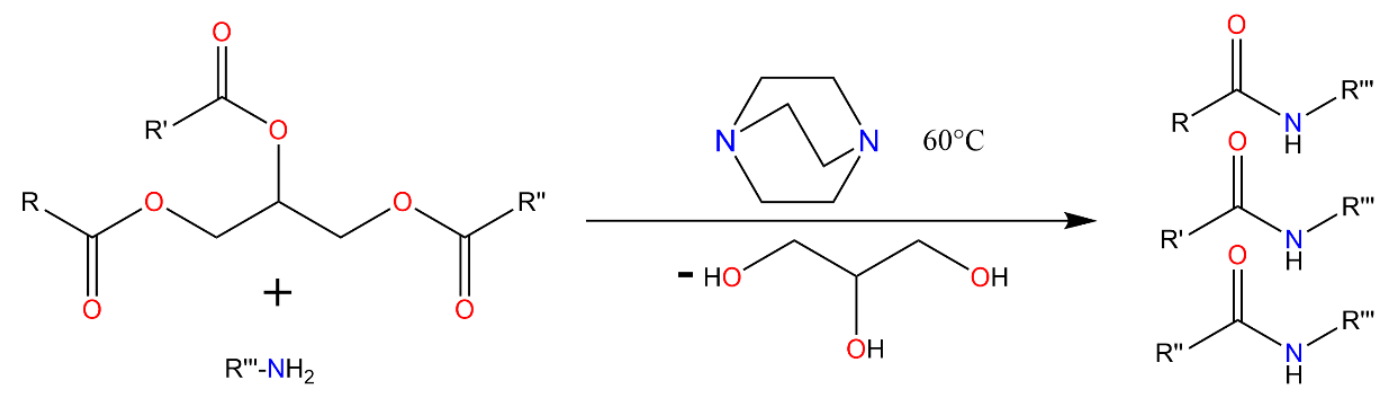

Figure S1. Scheme of the chemical reaction taking place in the synthesis of FAAm from vegetable oils and primary amines. 


\section{Green chemistry metrics}

Atom economy:

The AE measures the efficiency of the reaction in terms of how much of the reactants are incorporated into the desired product. This parameter is determined by dividing the molecular weight of the desired product by the sum of the molecular weight of the reactants. For a generic stoichiometric chemical reaction where $A$ and $B$ are the reactants, $\mathrm{C}$ is the desired product and $\mathrm{D}$ is a byproduct, $\mathrm{AE}$ is given by Eq. 1 [1].

$$
\begin{gathered}
A+B \rightarrow C+D \\
\% A E=\frac{M W_{C}}{M W_{A}+M W_{B}} \times 100
\end{gathered}
$$

Where MWC, MWA and MWB are the molecular weights of $C, A$ and $B$, respectively. Note that the chemical equation needs to be properly balanced before calculating $\mathrm{AE}$. This parameter finds its highest value $(100 \%)$ in the ideal case where the totality of the reactants remain in the desired product (no byproducts are generated). Since \%AE does not consider any other materials besides the reactants and does not contemplate the use of some of them in excess quantities, this metric is only a good indicator of the intrinsic waste associated with the reaction [1]. 
For FAAms from butylamine, the atom economy is given by:
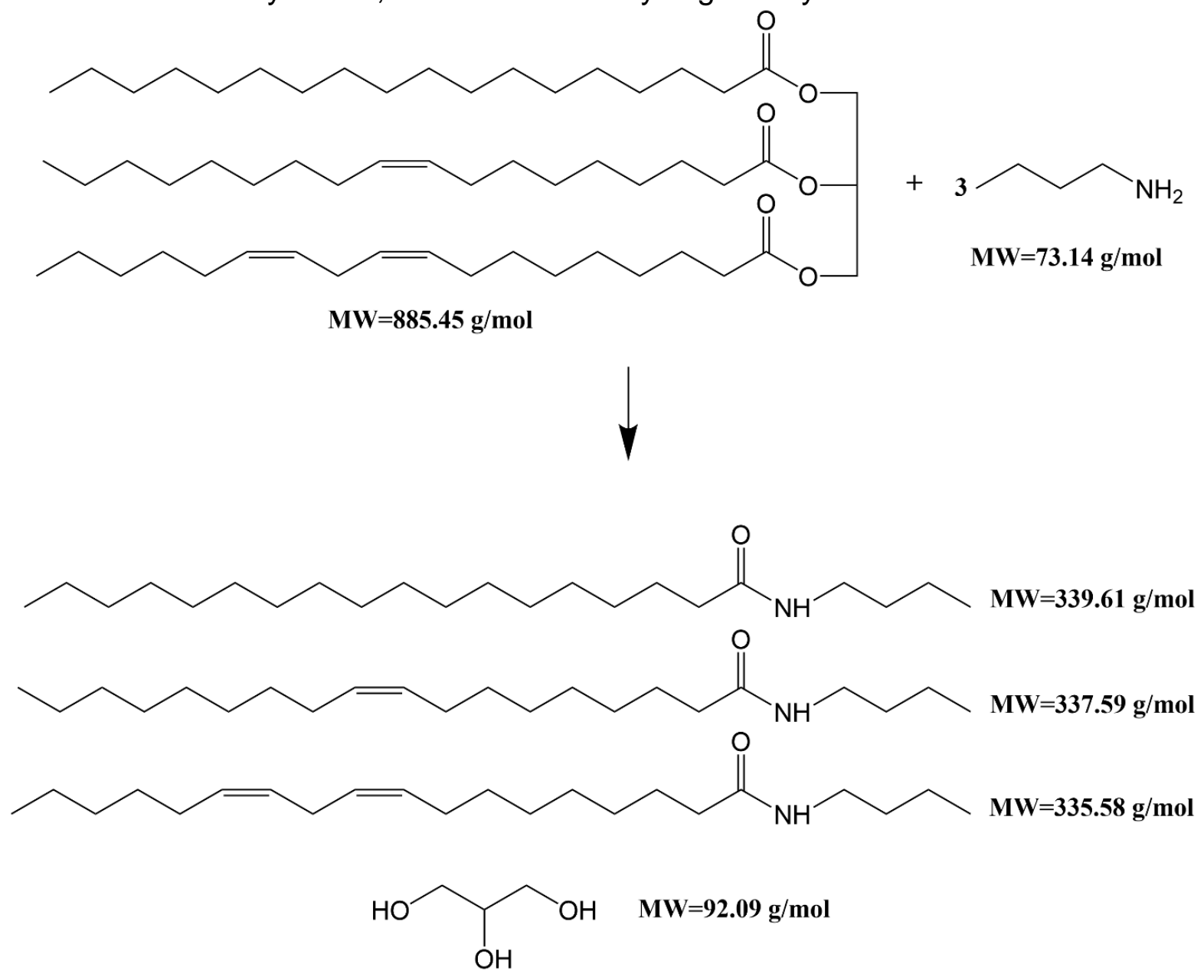

$$
\% A E=\frac{339.61+337.59+335.58}{885.45+3(73.14)} \times 100=91.7 \%
$$

The same procedure was followed to determine the \%AE for FAAms from octylamine, dodecylamine and hexadecylamine. 


\section{Environmental Factor:}

A much broader perspective can be obtained by calculating the $E$ factor $(E F)$, which accounts for the actual amount of reactants used in the organic preparation and other materials involved such as reagents and catalysts[2]. As a matter of fact, all substances used in the synthesis and generate waste should be considered in the E factor calculation. However, some ambiguity exists in the literature about the need to include water and any materials that can be recovered and/or recycled [1]-[3]. To avoid reporting any misleading results, two EF values proposed by Roschangar et al[3] were calculated in this article, the simple E factor (sEF) and the complete E factor (cEF). As seen in Eq. 2 [3], the former only considers the reactants and reagents used, leaving water and any solvents out of the calculation:

$$
s E F=\frac{\sum m(\text { Reactants })+\Sigma m(\text { Reagents })-\mathrm{m}(\text { Product })}{m(\text { Product })}
$$

Where $\mathrm{m}$ is the mass (in $\mathrm{Kg}$ ) of each substance. Alternatively, the complete $\mathrm{E}$ Factor takes into account all the reactants, reagents, catalysts, solvents, and water used for both synthesis and workup/purification even when some of these could be partially or totally recovered or recycled.[3]:

$$
c E F=\frac{\Sigma m(\text { Reactants })+\Sigma m(\text { Reagents })+\Sigma m(\text { Solvents })+\Sigma m(\text { Water })-\mathrm{m}(\text { Product })}{m(\text { Product })}
$$


Note that in both cases, the $\mathrm{E}$ factor is the ratio of waste generated respect to the amount of product obtained. Lower values of EF are preferred since they indicate a more efficient use of the materials, being 0 the ideal value (no waste). If reliable data exists about how much of the substances can be treated and/or recycled, these amounts can be subtracted from the numerator in Eq. 3 to determine the "true" E factor [3]. The cEF and the sEF then represent the upper and lower bounds of the amount of waste generated for any given synthesis, respectively. Amount of all the substances involved in the FAAm synthesis are listed in Table S1 and were used for the calculation of SEF and cEF parameters. 
Table S1. Substances used for the synthesis and purification of the FAAms

\begin{tabular}{ccccccc}
\hline FAAms & Oil $(\mathrm{g})$ & Amine $(\mathrm{g})$ & DABCO $(\mathrm{g})$ & \multicolumn{2}{c}{$\begin{array}{c}\text { Solvent used for } \\
\text { workup }(\mathrm{g})\end{array}$} & Amount of \\
& & & & & & \\
product $(\mathrm{g})$
\end{tabular}

For FAAms from corn oil and butylamine, the sEF is calculated using Eq. 2:

$$
s E F=\frac{4.0201+3.1571-3.2435}{3.2435}=1.21
$$


Alternatively, the cEF is determined using Eq. 3:

$$
s E F=\frac{4.0201+3.1571+0.02+139.35-3.2435}{3.2435}=44.18
$$

The procedure presented above was followed for all the other FAAms.

\section{EcoScale:}

Since \%AE and EF metrics only base the sustainability of the process on its intrinsic and extrinsic waste, respectively, Van Aken et al.[4] proposed the use of the EcoScale, a semiquantitative tool that takes into consideration other aspects of the organic preparation. The EcoScale goes from 0 to 100, where 100 represents the ideal green synthesis and lower values translate into less eco-friendly settings. This tool is based on a penalty system that subtract points from the preparation according to the yield \%, price of reaction components, safety of the materials, experimental setup, reaction conditions and ease of workup and purification. The amount of points subtracted according to each category will not be discussed here since they can be found elsewhere [4]. An example of the procedure used to calculate this parameter for FAAms from corn oil and butylamine is presented in Table S2. 
Table S2. Calculation of the EcoScale value for the preparation of FAAms from corn oil and butylamine.

Parameter

Penalty points

1. Yield: $70 \%$

15

2. Price of Reaction components $=\$ 0.23 / 10 \mathrm{mmol}$

0

3. Safety

Corn oil (not a hazardous substance)

0

Butylamine (highly flammable, toxic)

10

DABCO (flammable)

0

Water (not a hazardous substance)

0

4. Technical setup: common setup 0

5. Temperature/time: $60 \mathrm{C}$ for 72 hours 3

6. Workup/purification

$\begin{array}{ll}\text { Adding water } & 0\end{array}$

$\begin{array}{ll}\text { Decanting } & 0\end{array}$

Vacuum distillation 3

\begin{tabular}{ll}
\hline Total penalty points & 28
\end{tabular}

$\begin{array}{ll}\text { EcoScale Value } & 72\end{array}$ 
The same procedure described above was followed to determine the EcoScale value of all the other FAAms. Information needed for their calculations is provided in Tables S3 and S4. Note that the technical setup and the temperature and time of the reaction was the same for all the products.

Table S3. Hazard warnings of substances used in the syntheses of FAAms

\begin{tabular}{cc}
\hline Substance & Hazard warning ${ }^{*}$ \\
Corn oil & None \\
Sunflower oil & None \\
Palm oil & Highly flammable, Toxic \\
Butylamine & Toxic, Environmental effects \\
Octylamine & Toxic, Environmental effects \\
Dodecylamine & Environmental effects \\
Hexadecylamine & None \\
DABco & None \\
Ethanol & None \\
Water &
\end{tabular}

${ }^{*}$ Relevant to the EcoScale penalty system[4] 
Table S4. Relevant parameters of the FAAms synthesis for the EcoScale calculations

\begin{tabular}{|c|c|c|c|c|}
\hline FAAm & Yield & $\begin{array}{l}\text { Cost of reaction } \\
\text { components* }\end{array}$ & $\begin{array}{l}\text { Temperature and } \\
\text { time of reaction }\end{array}$ & Purification method \\
\hline $\mathrm{C}+4$ & $70 \%$ & $\$ 0.23$ & $73 \mathrm{~h}$ at $60^{\circ} \mathrm{C}$ & $\begin{array}{c}\text { Water rinsing, decanting, vacuum } \\
\text { distillation }\end{array}$ \\
\hline $\mathrm{C}+8$ & $85 \%$ & $\$ 0.70$ & $73 \mathrm{~h}$ at $60^{\circ} \mathrm{C}$ & $\begin{array}{c}\text { Water rinsing, decanting, vacuum } \\
\text { distillation }\end{array}$ \\
\hline $\mathrm{C}+12$ & $72 \%$ & $\$ 0.71$ & $73 \mathrm{~h}$ at $60^{\circ} \mathrm{C}$ & $\begin{array}{l}\text { Ethanol rinsing, recrystallizating, } \\
\text { vacuum filtering }\end{array}$ \\
\hline $\mathrm{C}+16$ & $78 \%$ & $\$ 0.59$ & $73 \mathrm{~h}$ at $60^{\circ} \mathrm{C}$ & $\begin{array}{l}\text { Ethanol rinsing, recrystallizating, } \\
\text { vacuum filtering }\end{array}$ \\
\hline$S+4$ & $77 \%$ & $\$ 0.21$ & $73 \mathrm{~h}$ at $60^{\circ} \mathrm{C}$ & $\begin{array}{c}\text { Water rinsing, decanting, vacuum } \\
\text { distillation }\end{array}$ \\
\hline $\mathrm{S}+8$ & $81 \%$ & $\$ 0.73$ & $73 \mathrm{~h}$ at $60^{\circ} \mathrm{C}$ & $\begin{array}{c}\text { Water rinsing, decanting, vacuum } \\
\text { distillation }\end{array}$ \\
\hline$S+12$ & $74 \%$ & $\$ 0.69$ & $73 \mathrm{~h}$ at $60^{\circ} \mathrm{C}$ & $\begin{array}{l}\text { Ethanol rinsing, recrystallizating, } \\
\text { vacuum filtering }\end{array}$ \\
\hline$S+16$ & $81 \%$ & $\$ 0.57$ & $73 \mathrm{~h}$ at $60^{\circ} \mathrm{C}$ & $\begin{array}{l}\text { Ethanol rinsing, recrystallizating, } \\
\text { vacuum filtering }\end{array}$ \\
\hline$P+4$ & $80 \%$ & $\$ 0.24$ & $73 \mathrm{~h}$ at $60^{\circ} \mathrm{C}$ & $\begin{array}{c}\text { Water rinsing, decanting, vacuum } \\
\text { distillation }\end{array}$ \\
\hline $\mathrm{P}+8$ & $83 \%$ & $\$ 0.76$ & $73 \mathrm{~h}$ at $60^{\circ} \mathrm{C}$ & $\begin{array}{c}\text { Water rinsing, decanting, vacuum } \\
\text { distillation }\end{array}$ \\
\hline$P+12$ & $70 \%$ & $\$ 0.55$ & $73 \mathrm{~h}$ at $60^{\circ} \mathrm{C}$ & $\begin{array}{l}\text { Ethanol rinsing, recrystallizating, } \\
\text { vacuum filtering }\end{array}$ \\
\hline$P+16$ & $83 \%$ & $\$ 0.50$ & $73 \mathrm{~h}$ at $60^{\circ} \mathrm{C}$ & $\begin{array}{c}\text { Ethanol rinsing, recrystallizating, } \\
\text { vacuum filtering }\end{array}$ \\
\hline
\end{tabular}

${ }^{*}$ Cost of reaction components needed to make $10 \mathrm{mmol}$ of product 
FTIR spectra of sunflower oil, palm oil and their respective FAAms

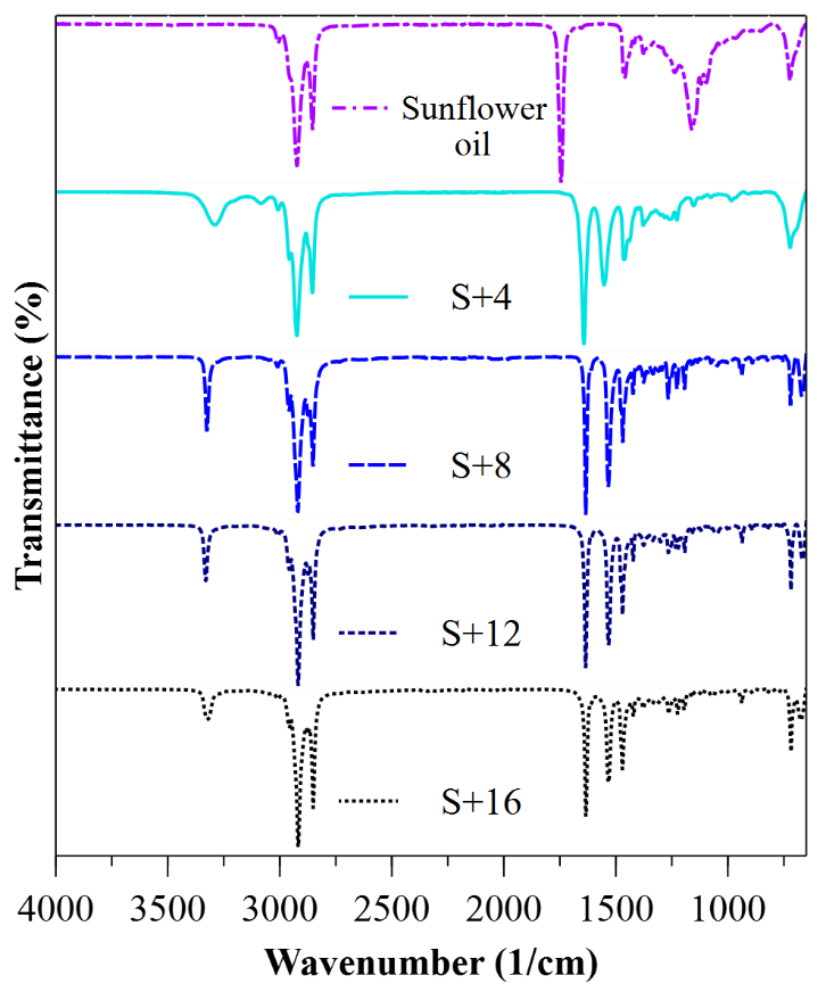

Figure S2. FT-IR spectra of sunflower oil and fatty acid amides (FAAms) from: sunflower oil and butylamine $(S+4)$, sunflower oil and octylamine $(S+8)$, sunflower oil and dodecylamine $(S+12)$ and sunflower oil and hexadecylamine $(\mathrm{S}+16)$. 


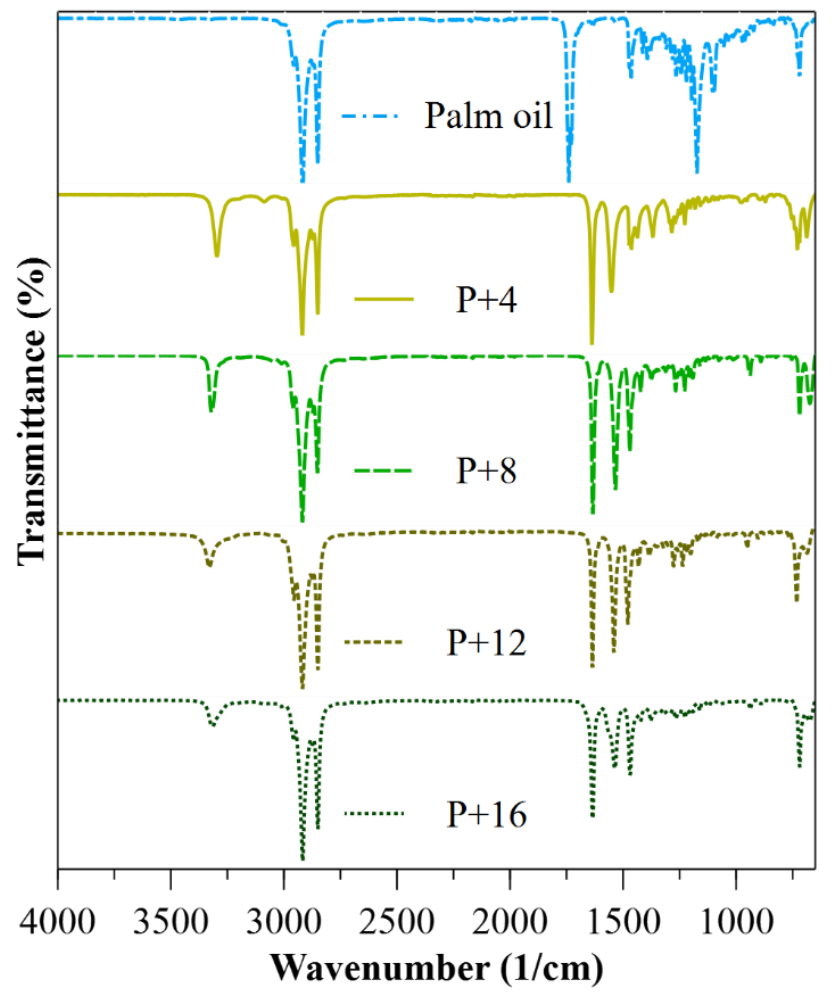

Figure S3. FT-IR spectra of palm oil and fatty acid amides (FAAms) from: palm oil and butylamine $(\mathrm{P}+4)$, palm oil and octylamine $(\mathrm{P}+8)$, palm oil and dodecylamine $(\mathrm{P}+12)$ and palm oil and hexadecylamine $(P+16)$. 
${ }^{13} \mathrm{C}$ NMR spectra of sunflower oil, palm oil and their respective FAAms

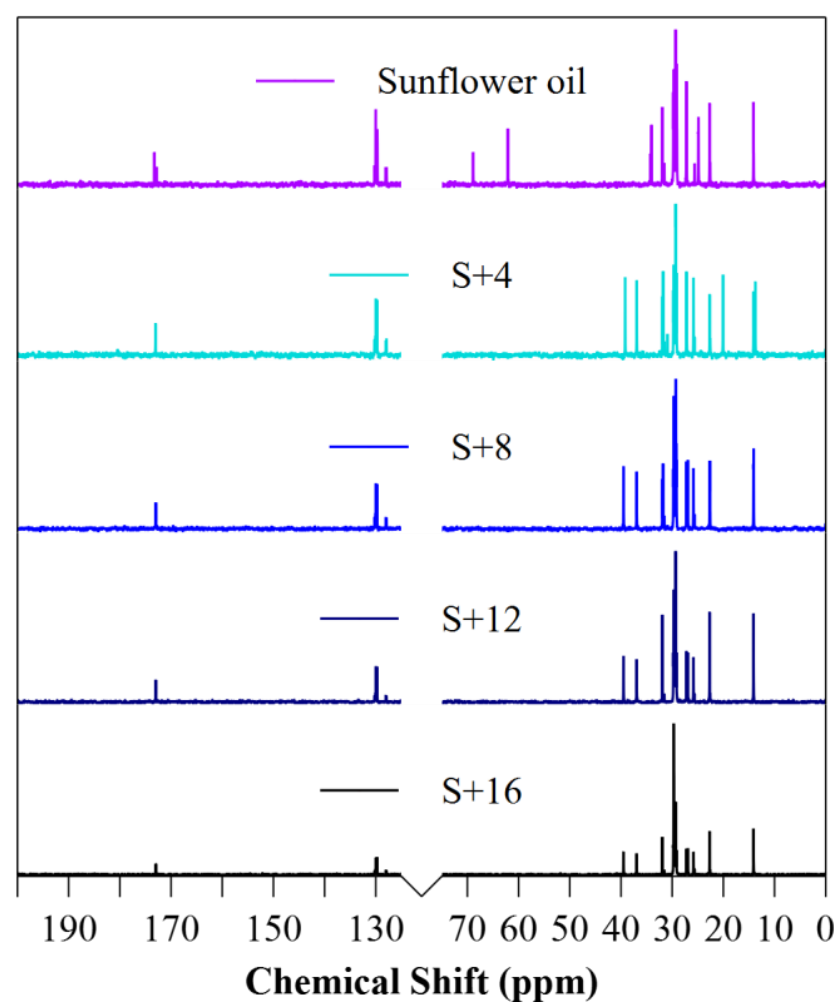

Figure S4. ${ }^{13} \mathrm{C}$ NMR spectra of sunflower oil and fatty acid amides from: sunflower oil and butylamine $(S+4)$, sunflower oil and octylamine $(S+8)$, sunflower oil and dodecylamine $(S+12)$ and sunflower oil and hexadecylamine $(\mathrm{S}+16)$. 


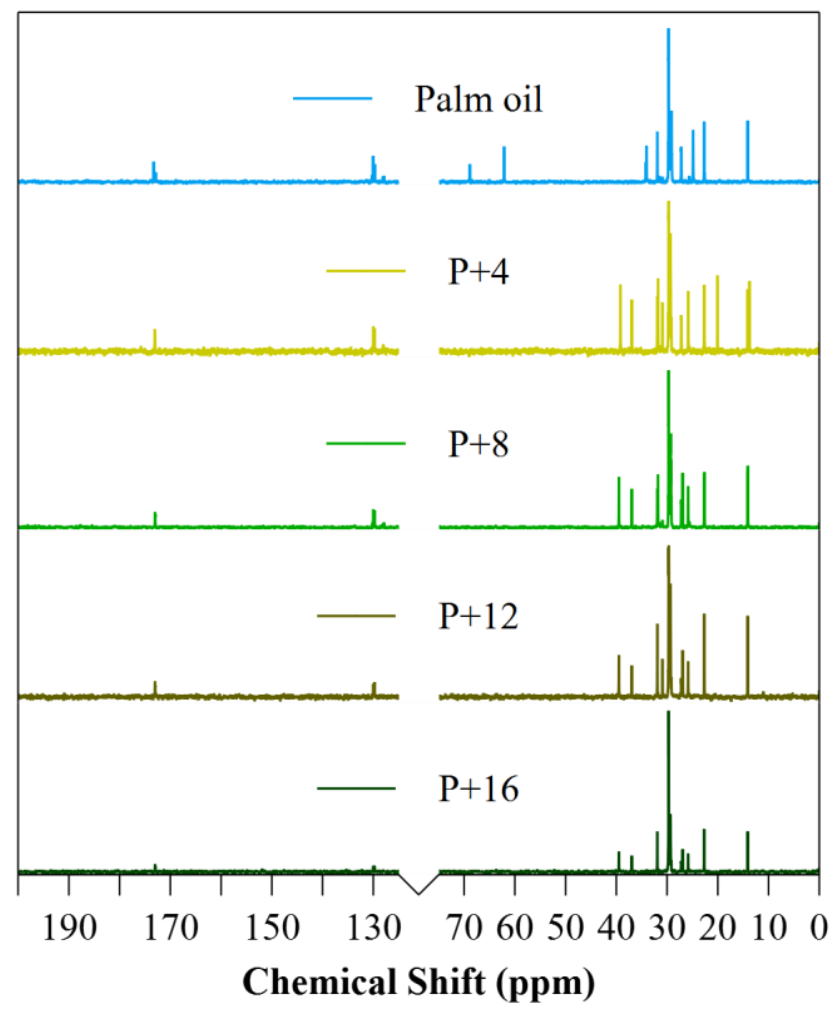

Figure S5. ${ }^{13} \mathrm{C}$ NMR spectra of palm oil and fatty acid amides from: palm oil and butylamine $(\mathrm{P}+4)$, palm oil and octylamine $(\mathrm{P}+8)$, palm oil and dodecylamine $(\mathrm{P}+12)$ and palm oil and hexadecylamine $(P+16)$. 
Integration of ${ }^{1} \mathrm{H}$ NMR spectra to determine acyl group composition of vegetable oils

The proportion of the different acyl groups contained in corn, sunflower and palm oil was determined from their ${ }^{1} \mathrm{H}$ NMR spectra following the procedure described by Guillen et al[5]. Figure $\mathrm{S} 6$ shows the ${ }^{1} \mathrm{H}$ NMR spectra of these oils where the signals observed were numbered and assigned to hydrogen atoms in the different functional groups detailed in Table S5.

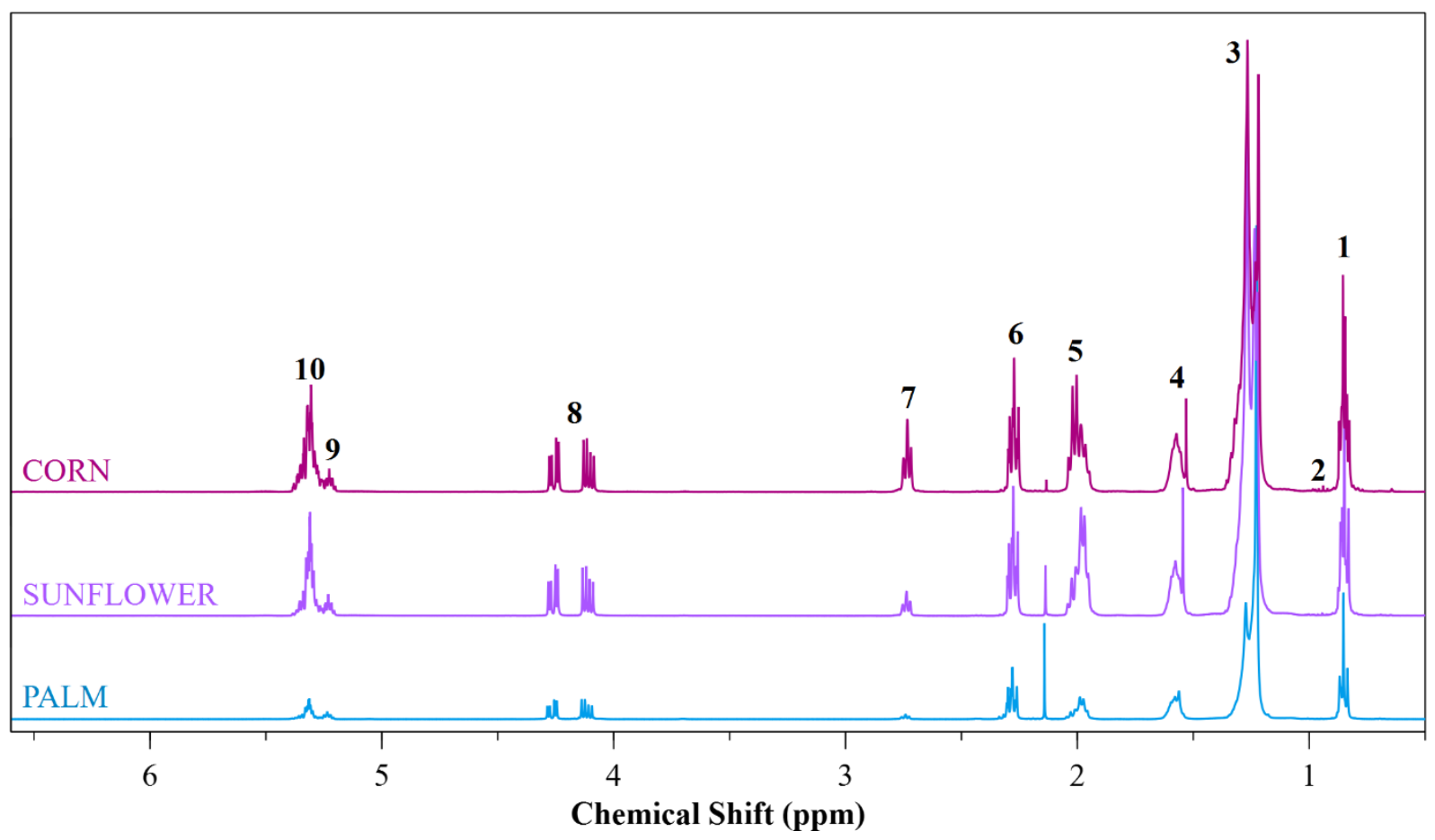

Figure S6. ${ }^{1} \mathrm{H}$ NMR spectra of corn, sunflower and palm oil samples. Signal numbering corresponds to that in Table S1. 
Table S5. Assignment of ${ }^{1} \mathrm{H}$ NMR signals to hydrogen atoms in different functional groups found in the triglyceride molecules of corn, sunflower and palm oil

\begin{tabular}{|c|c|c|c|}
\hline Signal & $\begin{array}{l}\text { Chemical } \\
\text { shift [ppm] }\end{array}$ & Functional group & $\begin{array}{c}\text { Segment of the triglyceride } \\
\text { containing the functional } \\
\text { group }\end{array}$ \\
\hline 1 & $0.80-0.87$ & $-\mathrm{CH}_{3}$ groups & $\begin{array}{l}\text { Saturated, oleic and linoleic } \\
\text { acid segments }\end{array}$ \\
\hline 2 & $0.93-1.03$ & $-\mathrm{CH}_{3}$ groups & Linolenic acid segments \\
\hline 3 & $1.21-1.36$ & $\begin{array}{l}-\mathrm{CH}_{2} \text { groups in } \beta \text { positions or } \\
\text { further respect to olefinic groups (- } \\
\qquad \mathrm{C}=\mathrm{C}-\text { ) and } \\
-\mathrm{CH}_{2} \text { groups in } \gamma \text { positions or } \\
\text { further respect to carbonyl groups } \\
\qquad(-\mathrm{C}=\mathrm{O})\end{array}$ & All acid segments \\
\hline 4 & $1.53-1.60$ & $\begin{array}{c}-\mathrm{CH}_{2} \text { - in } \beta \text { positions respect to } \\
\text { carbonyl groups }(-\mathrm{C}=\mathrm{O})\end{array}$ & All acid segments \\
\hline 5 & $1.95-2.05$ & $\begin{array}{c}-\mathrm{CH}_{2} \text { - in } \alpha \text { positions respect to a } \\
\text { single olefinic group (-C=C-) }\end{array}$ & $\begin{array}{l}\text { Oleic, linoleic and linolenic } \\
\text { acid segments }\end{array}$ \\
\hline 6 & $2.24-2.34$ & $\begin{array}{c}-\mathrm{CH}_{2} \text { - in } \alpha \text { positions respect to } \\
\text { carbonyl groups }(-\mathrm{C}=\mathrm{O})\end{array}$ & All acid segments \\
\hline 7 & $2.72-2.76$ & $\begin{array}{c}-\mathrm{CH}_{2-} \text { in } \alpha \text { positions respect to two } \\
\text { olefinic groups (-C=C-) }\end{array}$ & $\begin{array}{c}\text { Linoleic and linolenic acid } \\
\text { segments }\end{array}$ \\
\hline 8 & $4.08-4.29$ & $-\mathrm{CH}_{2}-$ groups & Glycerol segment \\
\hline 9 & $5.21-5.27$ & -CH- groups & Glycerol segment \\
\hline 10 & $5.27-5.39$ & $-\mathrm{CH}=\mathrm{CH}-$ groups & $\begin{array}{l}\text { Oleic, linoleic and linolenic } \\
\text { acid segments }\end{array}$ \\
\hline
\end{tabular}

The signal numbers agree with those in Fig. S6.

The magnitude of the signals in the spectra is proportional to the number of hydrogen atoms conforming each functional group. Since some of these functional groups are only present in certain fatty acid segments, their signals can be integrated to determine the 
fatty acid profile of the oils. For example, hydrogen atoms in methyl groups $\left(-\mathrm{CH}_{3}\right)$ will exhibit different chemical shifts depending on which acid segment they are part of. In the case of linolenic segments, this signal is observed around 0.93-1.03 ppm [5] (signal 2) while for all the other acid segments (saturated, oleic and linoleic) the signal is shifted downward to $0.83-0.93 \mathrm{ppm}$ (signal 1 in Figure S6). It must be noted that all acid segments independently of their unsaturation degree contain three hydrogen atoms in their methyl groups, contributing equally to this group's signal. Hence, the fraction of linolenic acid segments (Ln) with respect to the total amount of acid segments can be determined by Eq. 4, where A1 and A2 are the areas under signals 1 and 2, respectively.

$$
L n=\frac{A 2}{A 1+A 2}
$$

As illustrated in Figure S6, signal 2 is not clearly observed for any of the oils studied. Guillen et al.[5] reported that this specific signal can only be detected when the fraction of linolenic acid segments is above $0.4 \%$. The absence of signal 2 in these spectra indicates that the amount of linolenic acid segments in corn, sunflower and palm oils is very small or nonexistent. This result matches well with compositions found in literature and reported in Table 1.

Once the fraction of linolenic acid is known, the percentage of linoleic acid segments can be determined. Signal 7 corresponds to hydrogen atoms in bis-allylic positions or, in other words, hydrogen atoms in $\alpha$ positions respect to two olefinic groups. Bis-allylic protons are only found when two or more unsaturations exist, i.e., in linoleic and linolenic acid 
segments. Knowing that linolenic acid has two times the number of bis-allylic protons of linoleic acid, the fraction of linoleic acid segments $(L)$ is given by:

$$
L=\left(\frac{A 7}{A 6}\right)-2 L n
$$

Where $A 6$ and $A 7$ are the areas under signals 6 and 7, respectively. Note that signal 6 corresponds to protons in $\alpha$ positions respect to carbonyl groups $(\mathrm{C}=\mathrm{O})$, which are found in the same quantity for all acid segments independently of their degree of unsaturation. Then, the second term in Eq. 5 (A7/A6) represents the fraction of linolenic plus linoleic acid segments in the sample.

As shown in Table S5, signal 5 corresponds to hydrogen atoms in $\alpha$ positions respect to a single olefinic group, also known as allylic protons. Any acid segments with unsaturations contributes to this signal equally, since all of them have 4 protons of this type in their structures. Knowing the fractions of linoleic (L) and linolenic acid (Ln), the percentage of oleic acid segments $(\mathrm{O})$ can be determined using the following equation:

$$
O=\left(\frac{A 5}{2 A 6}\right)-(L+L n)
$$

Where A5 is the area under signal 5 in Figure S6. Note that in Eq. 6, A6 is multiplied by 2 since the number of allylic protons (4) is twice the number of protons in $\alpha$-positions to carbonyl groups (2) for each unsaturated acid segment contained in the sample. Finally, the percentage of saturated (S) acid segments can be calculated using Eq. 7: 


$$
S=1-\left(\frac{A 5}{2 A 6}\right)
$$

The area under each signal was determined by integrating the ${ }^{1} \mathrm{H}$ NMR spectra using the software TopSpin 3.6.2 by Bruker BioSpin. The obtained values are presented in Table S6 and were used along with Equations 1 to 4 to determine the fatty acid profile of the oils.

Table S6. Area of the signals of the ${ }^{1} \mathrm{H}$ NMR spectra of corn, sunflower and palm oils

\begin{tabular}{ccccccccccc}
\hline Oil & A1 & A2 & A3 & A4 & A5 & A6 & A7 & A8 & A9 & A10 \\
\hline Corn & 0.0889 & 0 & 0.5184 & 0.0686 & 0.1011 & 0.0595 & 0.0326 & 0.0402 & 0.0139 & 0.0768 \\
Sunflower & 0.0831 & 0 & 0.5618 & 0.0686 & 0.1044 & 0.0565 & 0.0107 & 0.0385 & 0.0110 & 0.0613 \\
Palm & 0.0829 & 0 & 0.6213 & 0.0673 & 0.0512 & 0.0574 & 0.005 & 0.0398 & 0.0100 & 0.0302 \\
\hline
\end{tabular}


Integration of ${ }^{1} \mathrm{H}$ NMR spectra to determine acyl group composition of the FAAms

The ${ }^{1} \mathrm{H}$ NMR spectra of the FAAms synthesized from corn, sunflower and palm oil are presented in Figures S7, S8 and S9, respectively. The signals were numbered and assigned to the different hydrogens found in the samples according to Table S7.

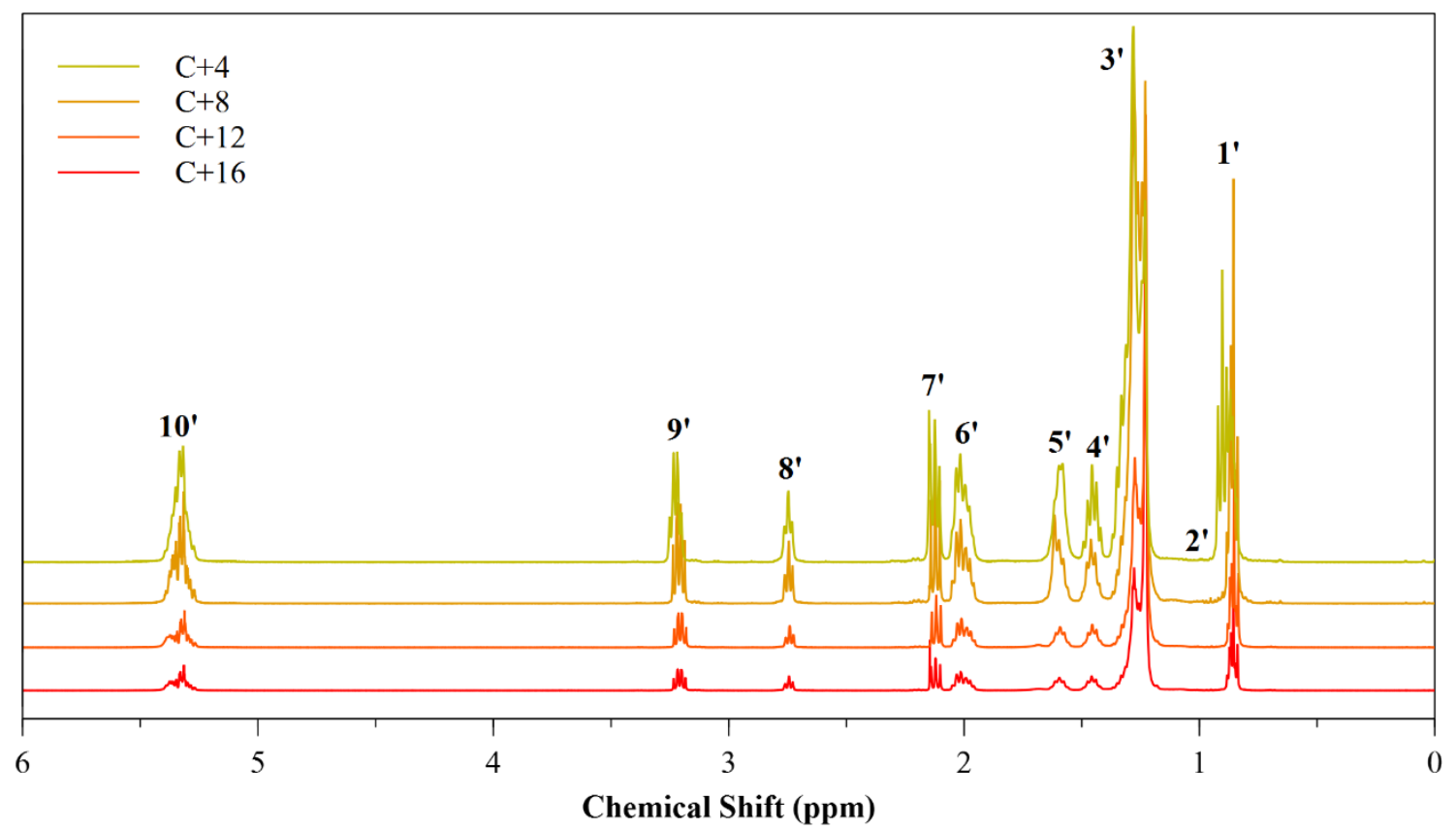

Figure S7. ${ }^{1} \mathrm{H}$ NMR spectra of FAAms synthesized from: corn oil and butylamine $(\mathrm{C}+4)$, corn oil and octylamine $(\mathrm{C}+8)$, corn oil and dodecylamine $(\mathrm{C}+12)$ and corn oil and hexadecylamine $(\mathrm{C}+16)$. Signal numbering corresponds to that in Table S3. 


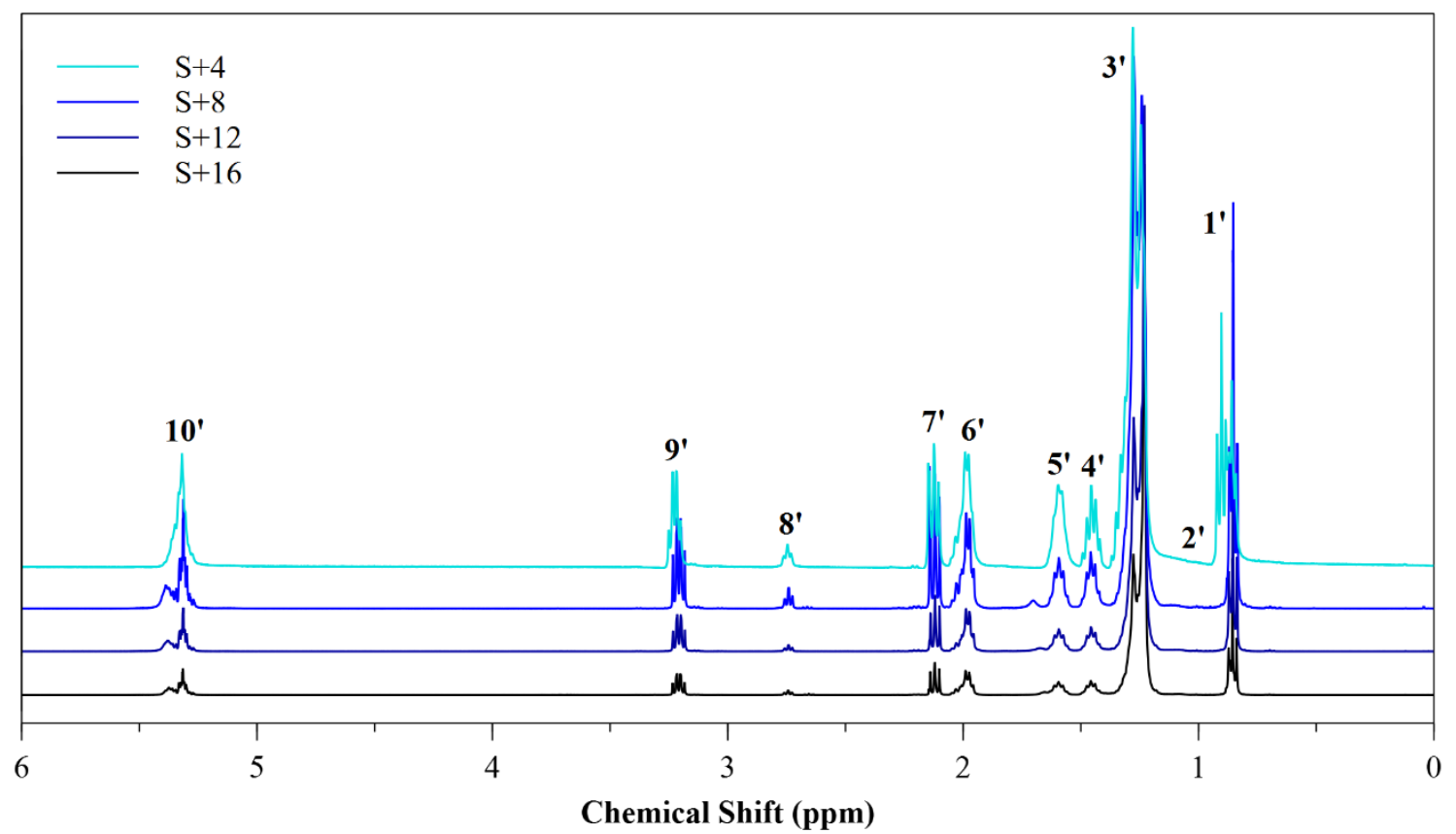

Figure S8. ${ }^{1} \mathrm{H}$ NMR spectra of FAAms synthesized from: sunflower oil and butylamine $(\mathrm{S}+4)$, sunflower oil and octylamine $(\mathrm{S}+8)$, sunflower oil and dodecylamine $(\mathrm{S}+12)$ and sunflower oil and hexadecylamine $(\mathrm{S}+16)$. Signal numbering corresponds to that in Table S3. 


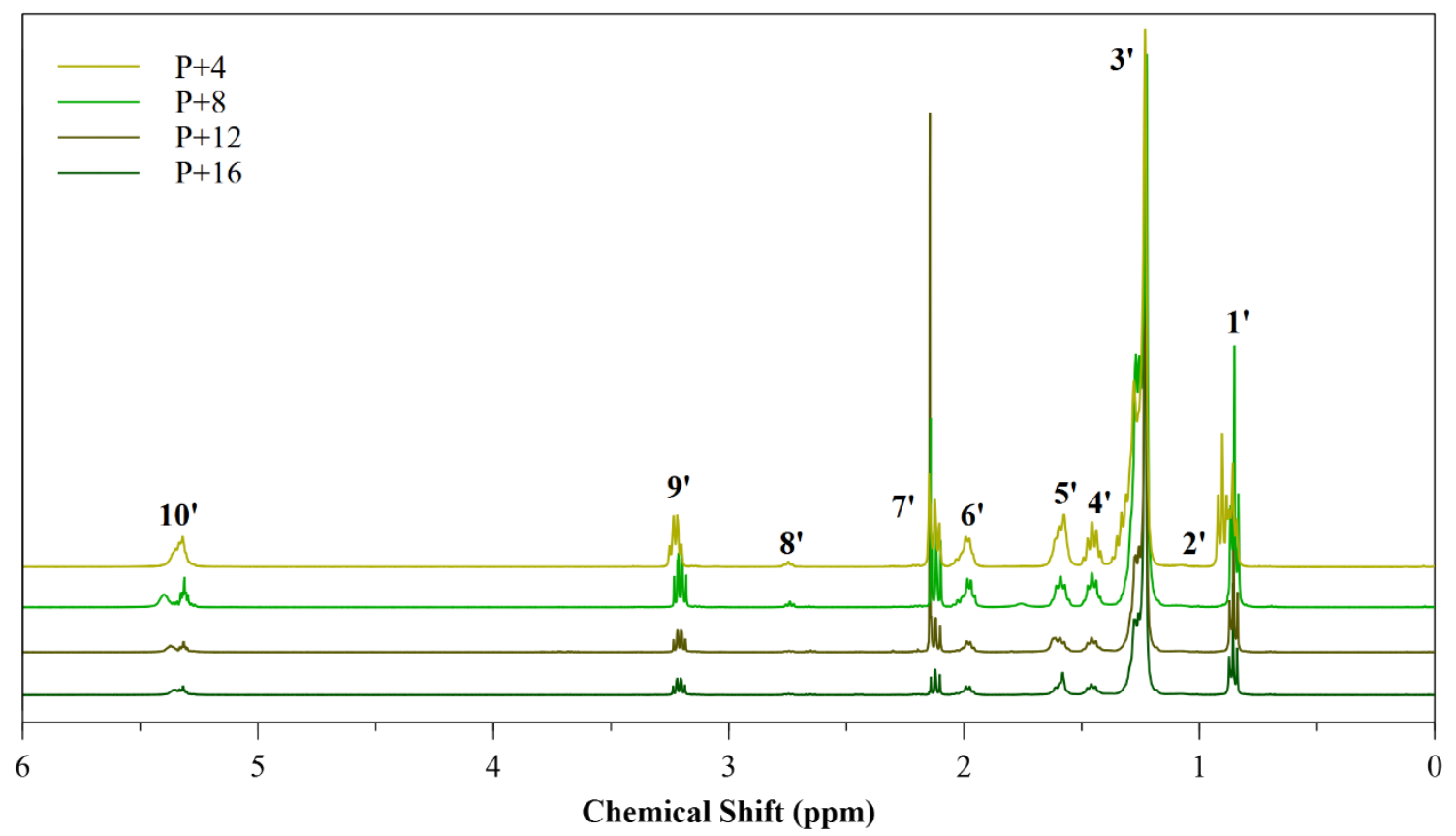

Figure S9. ${ }^{1} \mathrm{H}$ NMR spectra of FAAms synthesized from: sunflower oil and butylamine (S+4), sunflower oil and octylamine (S+8), sunflower oil and dodecylamine $(\mathrm{S}+12)$ and sunflower oil and hexadecylamine $(S+16)$. Signal numbering corresponds to that in Table S3. 
Table S7. Assignment of ${ }^{1} \mathrm{H}$ NMR signals to hydrogen atoms in different functional groups present in FAAms synthesized from corn, sunflower and palm oil

\begin{tabular}{|c|c|c|c|}
\hline Signal & $\begin{array}{l}\text { Chemical Shift } \\
{[\text { [ppm] }}\end{array}$ & Functional group & $\begin{array}{l}\text { Segments containing } \\
\text { the functional group }\end{array}$ \\
\hline 1 ' & $0.83-0.92$ & $-\mathrm{CH}_{3}$ & $\begin{array}{l}\text { Saturated, oleic and } \\
\text { linolenic segments }\end{array}$ \\
\hline $2^{\prime}$ & $\sim 1.09$ & $-\mathrm{CH}_{3}$ & Linolenic segments \\
\hline 3 & $1.22-1.35$ & $\begin{array}{l}-\mathrm{CH}_{2}-\text { in } \gamma \text { positions or further } \\
\text { respect to double bonded carbons } \\
\quad(-\mathrm{C}=\mathrm{O} \text { or }-\mathrm{C}=\mathrm{C}-)\end{array}$ & All segments \\
\hline $4^{\prime}$ & $1.41-1.49$ & $\begin{array}{l}-\mathrm{CH}_{2-} \text { in } \beta \text { positions respect to } \\
\text { olefinic groups (-C=C-) }\end{array}$ & $\begin{array}{c}\text { Oleic, linoleic and linolenic } \\
\text { segments }\end{array}$ \\
\hline $5^{\prime}$ & $1.55-1.62$ & $\begin{array}{c}-\mathrm{CH}_{2} \text { - in } \beta \text { positions respect to } \\
\text { amide group }(-\mathrm{NH}-\mathrm{C}=\mathrm{O})\end{array}$ & All segments \\
\hline $6^{\prime}$ & $1.95-2.00$ & $\begin{array}{c}-\mathrm{CH}_{2} \text { - in } \alpha \text { positions from olefinic } \\
\text { groups (-C=C-) }\end{array}$ & $\begin{array}{c}\text { Oleic, linoleic and linolenic } \\
\text { segments }\end{array}$ \\
\hline $7^{\prime}$ & $2.09-2.14$ & $\begin{array}{c}-\mathrm{CH}_{2-} \text { in } \alpha \text { positions from carbonyl } \\
\text { groups }(-\mathrm{C}=\mathrm{O})\end{array}$ & All segments \\
\hline $8^{\prime}$ & $2.72-2.77$ & $\begin{array}{c}-\mathrm{CH}_{2-} \text { in } \alpha \text { positions respect to two } \\
\text { olefinic groups (-C=C-) }\end{array}$ & $\begin{array}{c}\text { Oleic, linoleic and linolenic } \\
\text { segments }\end{array}$ \\
\hline $9^{\prime}$ & $3.18-3.25$ & $\begin{array}{c}-\mathrm{CH}_{2-} \text { in } \alpha \text { positions respect to - } \\
\mathrm{NH} \text { - groups }\end{array}$ & All segments \\
\hline $10^{\prime}$ & $5.26-5.40$ & -CH- in olefinic groups & $\begin{array}{c}\text { Oleic, linoleic and linolenic } \\
\text { segments }\end{array}$ \\
\hline
\end{tabular}

The signal numbers agree with those in Figures S2, S3 and S4.

All the samples independently of their precursor amine or oil exhibited the same characteristic signals. Nonetheless, variations in their relative magnitudes were observed due to differences in their compositions. The fatty acid profile of each FAAm was determined after making some slight changes to the procedure described in the previous 
section. First, the fraction of linolenic segments $(L n)$ in the sample was calculated from the signals corresponding to methyl $\left(-\mathrm{CH}_{3}\right)$ groups in the same way it was done for the oils:

$$
L n=\frac{A 2^{\prime}}{A 1^{\prime}+A 2^{\prime}}
$$

Where A1' and A2' are the areas of signals 1' and 2', respectively (Figs. S7, S8, S9). It must be noted that signal 2' is not observed in any of the spectra. This was to be expected since the precursor oils for these FAAms don't have linolenic segments in their compositions. Next, the percentage of linoleic acid was computed by calculating the fraction of segments with 2 or more unsaturations and then subtracting the fraction of linolenic acid segments:

$$
L=\left(\frac{A 8^{\prime}}{A 9^{\prime}}\right)-2 L n
$$

Where A8' and A9' are the areas under signals 8 and 9, respectively. Note that signal 8' corresponds to bisallylic protons, which are only found on segments with two or more unsaturations (linolenic and linoleic). Signal 9' corresponds to protons in $\alpha$ positions respect to $\mathrm{N}-\mathrm{H}$ bonds, which are found in the same quantity for all acid segments independently of their degree of unsaturation. Then, second term in Eq. 9 (A8'/A9') represents the fraction of bisallylic protons respect to all acid segments in the sample. Two times the fraction of linolenic segments is then subtracted since linolenic segments have twice as many bisallylic protons as their linoleic counterparts. 
All unsaturated acid segments have 4 allylic protons in their structure; hence, once the fractions of linolenic and linoleic acid segments are known, the percentage of oleic acid (O) can be determined using Eq. 10:

$$
O=\frac{A 6^{\prime}}{2 A 9^{\prime}}-(L+L n)
$$

Where $S^{\prime} 6^{\prime}$ is the area under signal $6^{\prime}$. Note that $A 6^{\prime}$ is divided by 2 since for any unsaturated segment there are twice as many allylic protons as there are $\alpha$-protons respect to $-\mathrm{NH}$ - groups. Finally, the fraction of saturated segments $(\mathrm{S})$ is calculated using Eq. 11:

$$
S=1-\left(\frac{A 6 \prime}{A 9 \prime}\right)(
$$

The fatty acid profile of the synthesized FAAm was then determined from Eq. 8 to 11 and values in Table S8. 
Table S8. Area of the signals of the ${ }^{1} \mathrm{H}$ NMR spectra of FAAms synthesized from corn (C), sunflower (S) and palm oils (P) and butylamine (4), octylamine (8), dodecylamine (12) and hexadecylamine (16)

\begin{tabular}{ccccccccccc}
\hline $\begin{array}{c}\text { FAAm } \\
\text { from: }\end{array}$ & A1' & A2' & A3' & A4' & A5' & A6' & A7' & A8' & A9' & A10 \\
\hline C+4 & 1.6525 & 0.0000 & 5.4141 & 0.6001 & 0.8586 & 0.9637 & 0.7122 & 0.3159 & 0.5399 & 1.0000 \\
C+8 & 0.1124 & 0.0000 & 0.5407 & 0.0416 & 0.0574 & 0.0622 & 0.0374 & 0.0189 & 0.0365 & 0.0661 \\
C+12 & 1.0000 & 0.0000 & 6.2273 & 0.3674 & 0.3557 & 0.5486 & 0.3355 & 0.1660 & 0.3385 & 0.5832 \\
C+16 & 0.0879 & 0.0000 & 0.6646 & 0.0320 & 0.0324 & 0.0499 & 0.0287 & 0.0157 & 0.0292 & 0.0532 \\
S+4 & 0.1370 & 0.0000 & 0.5065 & 0.0489 & 0.0480 & 0.0845 & 0.0478 & 0.0095 & 0.0453 & 0.0725 \\
S+8 & 0.1158 & 0.0000 & 0.5798 & 0.0431 & 0.0408 & 0.0709 & 0.0444 & 0.0075 & 0.0381 & 0.0597 \\
S+12 & 1.0045 & 0.0000 & 6.5835 & 0.3734 & 0.3684 & 0.6084 & 0.3483 & 0.0466 & 0.3364 & 0.5000 \\
S+16 & 0.0864 & 0.0000 & 0.6943 & 0.0339 & 0.0323 & 0.0523 & 0.0289 & 0.0049 & 0.0282 & 0.0438 \\
P+4 & 2.9324 & 0.0000 & 12.0714 & 1.0906 & 1.6194 & 0.9230 & 1.4499 & 0.1151 & 1.0206 & 1.0000 \\
P+8 & 0.1175 & 0.0000 & 0.6430 & 0.0428 & 0.0414 & 0.0347 & 0.0388 & 0.0036 & 0.0388 & 0.0394 \\
P+12 & 0.0979 & 0.0000 & 0.6875 & 0.0365 & 0.0523 & 0.0235 & 0.0386 & 0.0016 & 0.0329 & 0.0293 \\
P+16 & 0.0840 & 0.0000 & 0.7097 & 0.0304 & 0.0458 & 0.0231 & 0.0281 & 0.0017 & 0.0282 & 0.0259 \\
\hline
\end{tabular}


TGA diagrams of methyl laurate and FAAms from corn oil and butylamine

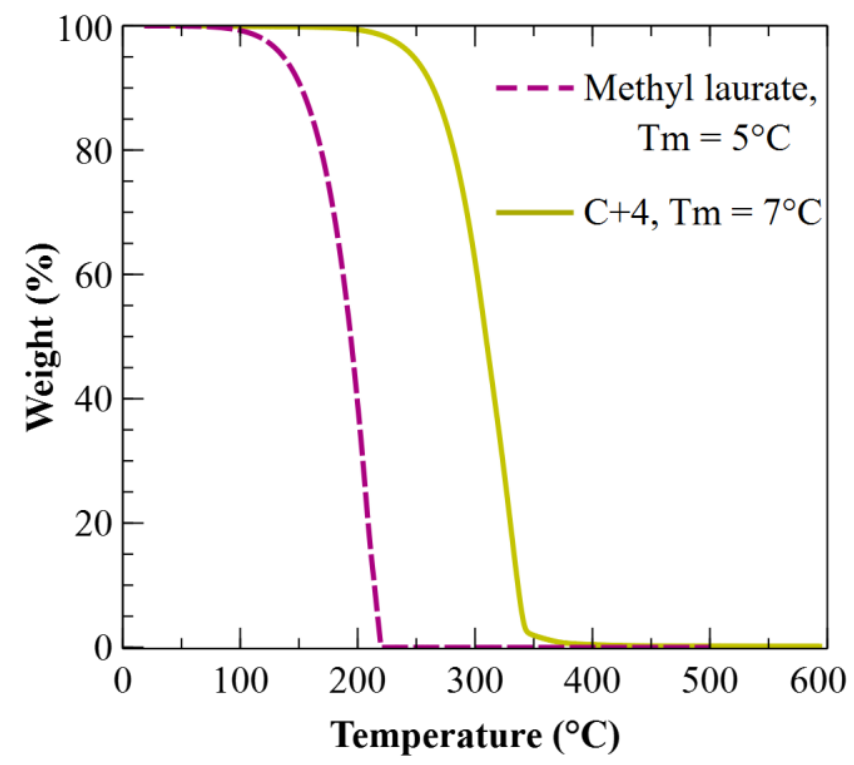

Figure S10. TGA diagram of methyl laurate and FAAms from corn oil and butylamine $(\mathrm{C}+4)$. 


\section{REFERENCES}

[1] A. P. Dicks and A. Hent, Green Chemistry Metrics. Cham: Springer International Publishing, 2015.

[2] R. A. Sheldon, "Metrics of Green Chemistry and Sustainability: Past, Present, and Future," ACS Sustainable Chemistry and Engineering, vol. 6, no. 1. American Chemical Society, pp. 32-48, 02-Jan-2018.

[3] F. Roschangar, R. A. Sheldon, and C. H. Senanayake, "Overcoming barriers to green chemistry in the pharmaceutical industry-the Green Aspiration Level ${ }^{\mathrm{TM}}$ concept," Green Chem., vol. 17, no. 2, pp. 752-768, 2015.

[4] K. Van Aken, L. Strekowski, and L. Patiny, "EcoScale, a semi-quantitative tool to select an organic preparation based on economical and ecological parameters," Beilstein $\mathrm{J}$. Org. Chem., vol. 2, no. 3, 2006.

[5] M. D. Guillén and A. Ruiz, "1H nuclear magnetic resonance as a fast tool for determining the composition of acyl chains in acylglycerol mixtures," Eur. J. Lipid Sci. Technol., vol. 105, no. 9, pp. 502-507, Sep. 2003. 